\title{
Separation of Flood Plain Flow: 1-D Momentum Equation Solver
}

\author{
Shiblu Sarker ${ }^{1^{*}}$ \\ ${ }^{1}$ St. Johns River Water Management District,Florida, 32177, USA; ORCID: \\ 0000-0001-5580-2498 \\ *Author's email: shiblu. buet@gmail.com
}

\begin{abstract}
A floodplain is an area of land close to a stream or river that extends from its banks to the valley walls or high mountains surrounding it. It is frequently inundated during periods of high runoff. Along with the main stream, a large volume of flow passes through this floodplain during flood discharge. The term "floodplain flow" refers to this redundant discharge. When studying the hydromorphodynamics of a river from bank to bank, it is necessary to understand the flow distribution throughout the main stream and flood plain. The main stream's water level and discharge are critical parameters for estimating river bank erosion. As a result, the floodplain may operate as a sediment sink during periods of high flow. River hydraulic and hydrodynamic processes are intricate. There are numerous river modeling tools and approaches available for evaluating the distribution and generation of river flow over floodplain and main-stream. This study examines such two methods for generating river flow over the flood plain and in the main stream. The approaches involve the use of a one-dimensional momentum equation and a twodimensional modeling tool (Mike21C) to generate main-stream and flood plain flow. The Kalni-Kushiyara river is chosen as a case study in order to determine its validity.
\end{abstract}

\section{Introduction}

A flood plain is a region that is flooded on a regular basis by water coming from a local river or from the river network within a watershed Sarker et al. (2019); Sarker (2021b). The majority of floodplains are produced through deposition inside river meanders and overbank flow. There is a knowledge gap on the hydraulics of overbank flows. Researchers now know the most of what we know about water flow in floodplain areas from experimental or statistical studies. The discharge associated with the bank-full stage might well be calculated using a stage-discharge rating curve constructed from collected data. When flood plain conveyance is substantial in comparison to channel conveyance, the stage discharge rating curve will exhibit a noticeable break at bank-full stage Dottori et al. (2009); Koussis (2009); Reitan and Petersen-Øverleir (2011); Morlot et al. (2014). This arrangement arises because, in alluvial streams, stage is a unique function of discharge Sarker (2021a,d,c). As a result, estimating a rating curve is considerably simpler. However, complicated scenarios often emerge as a result of the sporadic and unexpected occurrence of floods, especially big ones, the short duration of overbank flows, and the inherent risks associated with taking measurements during flood discharges. Due to the complexity of flow conditions, measurements of flow may vary during severe events. While calculating the hydraulics of flood flows on a real river is very complex, it is important for practical reasons such as assessing a channel's and floodplain's conveyance capacity or forecasting flood route.

The aim of this article is to provide a practical, precise, and predictable tool for flood flow separation that is based on the momentum equation.

\section{Study Area}

The Kalni River has a substantial flood plain, and bathymetric data are available that are suitable for our techniques. The Kalni-Kushiyara River system starts in India, on the banks of the Barak River. The Barak River flows through Assam, Manipur, and Mizoram in India. The river then enters Bangladesh near Amalshid, where it divides into the south-flowing Kushiyara River. The river is known as the Kalni River downstream 
of Markuli. In a tiny section of the Kalni River, the 1D and 2D-momentum techniques are used. Following that, comparisons of these two approaches are discussed. The Kalni-Kushiyara River management project provided all data for this section of the Kalni River (see figure 1).

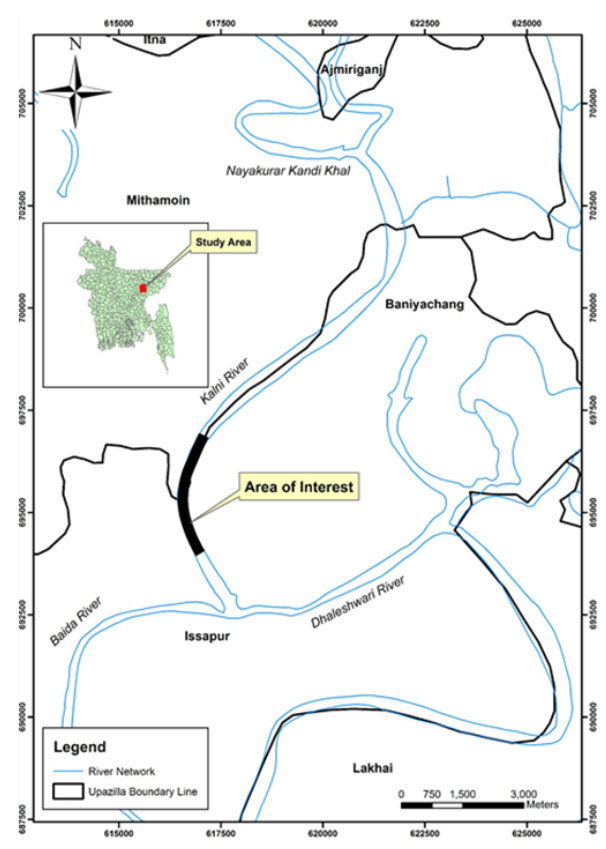

Figure 1: Area of study for the Kalni River segment.

\section{Methods}

In this section we aim to explains and formulation of our proposed 1-D method and the governing equation, that has been adjusted to generate discharge using only water level, cross-sectional, and roughness inputs for a small reach. This technique adopted convective acceleration and a change in the slope of the water surface. The governing equation is numerically solved by discretizing cross-sections relative to the water level (see details in Reza et al. (2014)). This numerical solution and data management were carried out by an application developed in VBA (Visual Basic for Applications). A two-dimensional model is also adjusted from collected 2-D morphological model from the IWM library in connection with the Kalni-Kushiyara River management project. Finally, the extracted discharge was calibrated against the 2-D discharge of selected study portion using statistical test (t-test Sarker (2021b)).

\subsection{1-D Governing Equation}

This approach is governed by the 1-D momentum equation (see 1), the differential form of momentum equation can be simplified for small longitudinal direction only. This momentum equation is composed of three types of forces (Pressure, Gravity, and Friction (see details in Reza et al. (2014); Sarker (2021d))), each of which produces two distinct types of acceleration (Convective acceleration and Local acceleration Sarker (2021d)). This simplified 1-D momentum equation can be written as:

$$
\frac{\partial Q}{\partial t}+\frac{\partial}{\partial t}\left(\frac{Q^{2}}{A}\right)+g A \frac{\partial h}{\partial x}-g A\left(S-S_{f}\right)=0
$$

Carrying out the above mentioned steps with regard to the momentum correction factor, water surface slope compared to the datum, and making use of both discharge and cross section characteristics, the equation simplifies to:

$$
\frac{\partial z}{\partial x}+\frac{1}{2 g} \frac{\partial}{\partial x}\left(\frac{\beta Q^{2}}{A^{2}}\right)+\frac{1}{g} \frac{\partial\left(\frac{Q}{A}\right)}{\partial t}+\frac{Q^{2}}{K^{2}}=0
$$


where $x=$ longitudinal distance along the reach, $t=$ the time coordinate, $z=z_{0}+h$ vertical distance of water surface from the horizontal datum, $z_{0}$ is the vertical distance of bed from the horizontal datum, $\beta=$ momentum correction factor, $A=$ cross-sectional area and $K=$ conveyance of the section.

This calculation works nearly exactly when the water level fluctuates substantially over time. The Momentum Correction Factor $(\beta)$ is contingent on the overall cross sectional conveyance characteristics. There are an large number of tiny parts in each cross section.

$$
K=\sum_{j=1}^{N} K_{j}=\frac{1}{N} \sum_{j=1}^{N} A_{j} R_{j}^{\frac{2}{3}}
$$

where $K_{j}=$ Conveyance of the tiny area of each cross section, $A_{j}=$ Area of the small pocket, $R_{j}=$ Hydraulic radius of the small pocket and $n=$ Manning's roughness. While the momentum coefficient can be estimated as

$$
\beta=\frac{1}{U^{2} A} \int_{0}^{A} u^{2} d A \cong \frac{A}{K^{2}} \sum_{j=1}^{N} \frac{K_{j}^{2}}{A_{j}}
$$

\subsection{Solution of the 1-D Governing Equation}

It is anticipated that no noticeable discharge is going to enter or leave the region that is separated by the gap between the two adjacent portions. That means that if cross sections for a straight stretch are straight and sufficiently near, then the equation 2 may be reduced. Thus, modest longitudinal discharge fluctuation is a possible explanation for the variance in discharge seen in this instance Reza et al. (2014); Dottori et al. (2009).

$$
\left(h_{u}-h_{d}\right)+\frac{Q^{2}}{2 g}\left(\frac{\beta_{u}}{A_{u}^{2}}-\frac{\beta_{d}}{A_{d}^{2}}\right)+\frac{x_{u}-x_{d}}{2}\left(\frac{1}{K_{u}^{2}}+\frac{1}{K_{d}^{2}}\right) Q^{2}+\left(x_{u}-x_{d}\right) \frac{\partial \frac{Q}{A}}{\partial t}=0
$$

The solution reduces to a quadratic equation, representing a single unknown discharge, when the local acceleration is ignored in equation 5 . It may be written as:

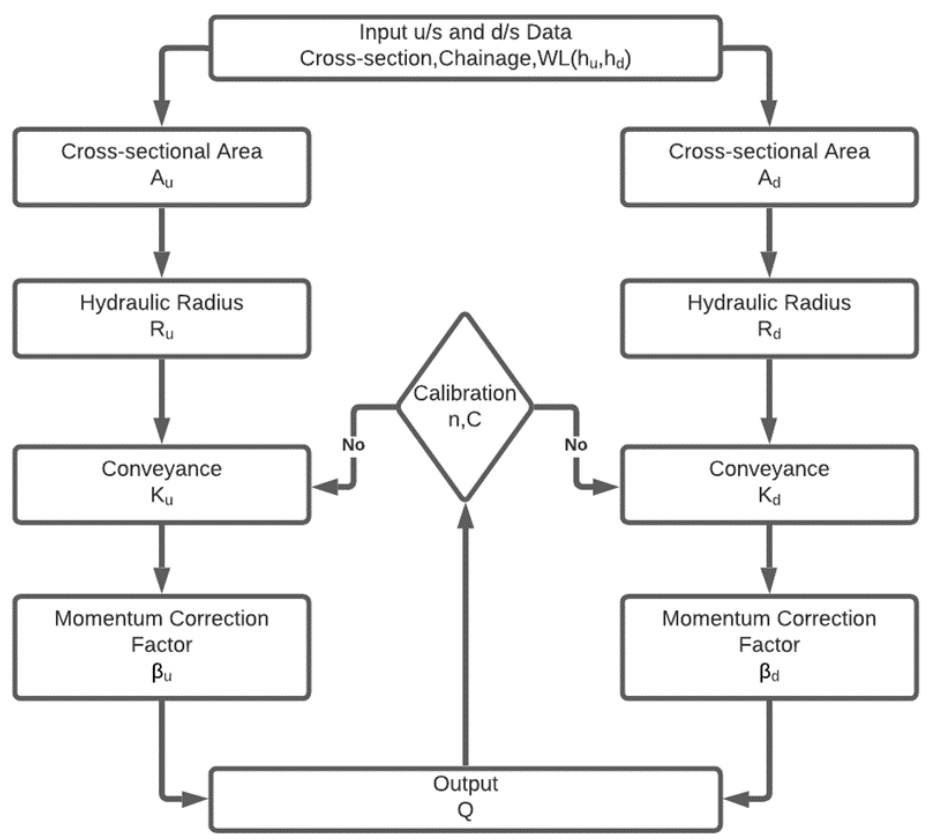

Figure 2: The flow chart of algorithms. 


$$
\left(h_{u}-h_{d}\right)+\frac{Q^{2}}{2 g}\left(\frac{\beta_{u}}{A_{u}^{2}}-\frac{\beta_{d}}{A_{d}^{2}}\right)+\frac{x_{u}-x_{d}}{2}\left(\frac{1}{K_{u}^{2}}+\frac{1}{K_{d}^{2}}\right) Q^{2}=0
$$

Numerical solutions are used to solve the equation for different water level variations while implementing a Visual Basic application. This flowchart shows the solution algorithm:

Only by calibrating the Chezy's $C$ for given water level, cross-section, and chainage data upstream and downstream can one find the discharge within the reach Reza et al. (2014). This method is shown in the next section.

\subsection{2-D Model (MIKE 21C) Setup}

Two-dimensional model set up consists of selection of model domain, generation of computational grid, generation of model bathymetry, generation of the water level-discharge boundaries and selection of simulation period.

MIKE 21C combines the hydrodynamic model and morphological model in mobile bed condition. In this model, mass conservation is done in both longitudinal and transverse direction and momentum conservation equation using Renolds Depth Average Navier-Stokes formula which calculates momentum transfer in both direction. The surveyed bankline of Kalni-Kushiyara river has been used to generate computation curvilinear grids (shown in figure 4). The Kalni-Kushiyara River bathymetry was obtained by superimposing the surveyed bathymetry data on the curvilinear grid. The speciality of curvilinear grid is to simulate the streamline curvature with the flow and as well as sediment movement in both longitudinal and transverse direction. To solve the mass balance accurately, the 2-D model was done in several sub-models. Bathymetry of the model contains the cross section of river including flood plain. The upstream discharge and downstream water level boundary was collected from 1-D North-East regional model of IWM. The simulation period has been considered from 1-January 2011 to 31-December 2011.

\section{Input Data}

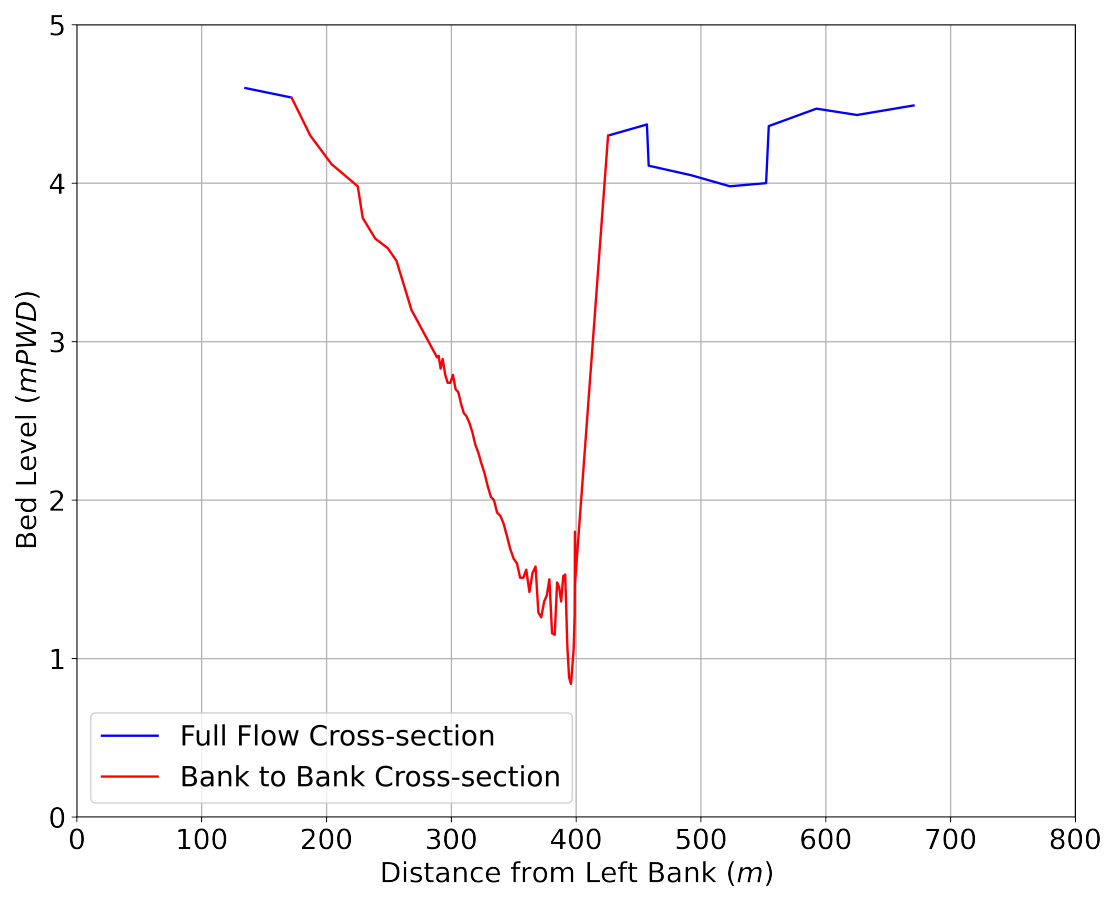

Figure 3: U/S Cross-section. 


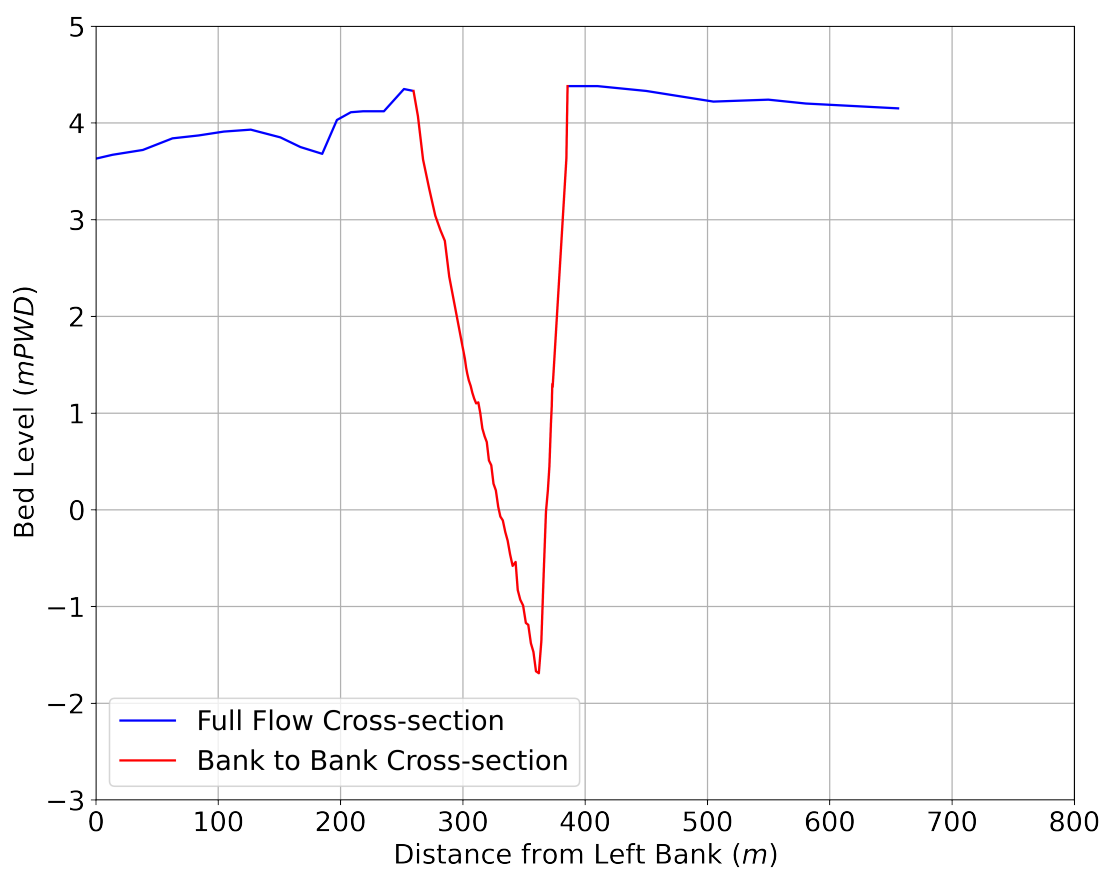

Figure 4: D/S Cross-section.

In order to investigate the ability of the suggested tool for the separation of flood plain flow from observed discharge, we have picked a short reach (which was described in the previous section) that will allow us to test it. We have chosen one $\mathrm{u} / \mathrm{s}$ cross section and one $\mathrm{d} / \mathrm{s}$ cross section from figure 3 and another from figure 4. Additional information in the form of a cross sectional water level hydrograph can be seen in figure 5 .

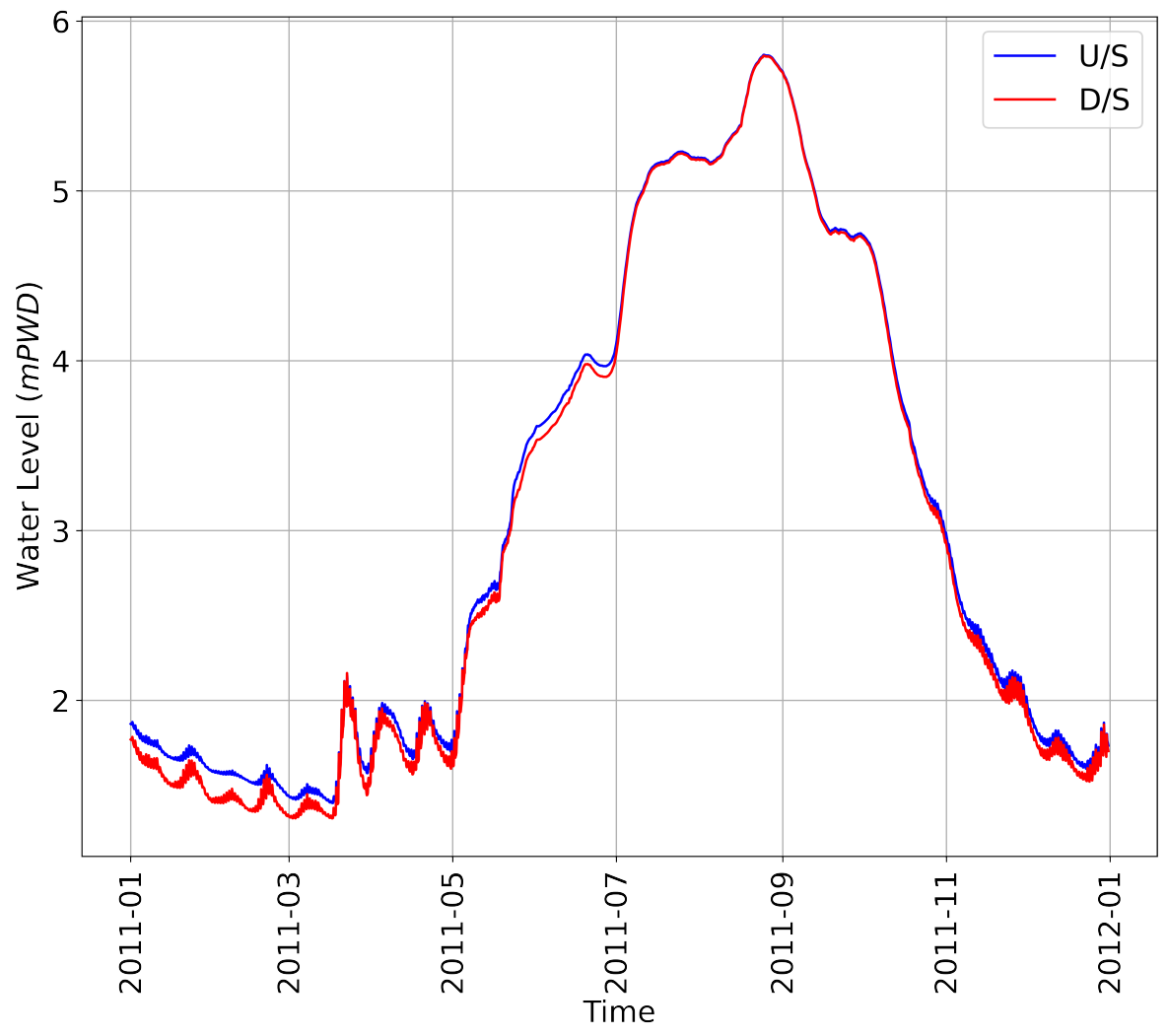

Figure 5: Water Level Hydrograph. 


\section{Results and Discussion}

Figure 6 showed how the bank to bank discharge simulated using our proposed method compared to the bank to bank discharge from the MIKE 21C. It is important to point out that a significant linear relationship (slope $=1.08$ ) was observed from their comparison with $R^{2}$ value of 0.99 , in addition, $t$ test results show a significant correlation with a $95 \%$ confidence interval Sarker (2021b). Hence, one can separate flood plain flow from the observed discharge depicted in the figure 6. Therefore, our proposed technique can be used where bank to bank flow and flood plain flow separation is necessary due to hydrologic or morphological purposes.

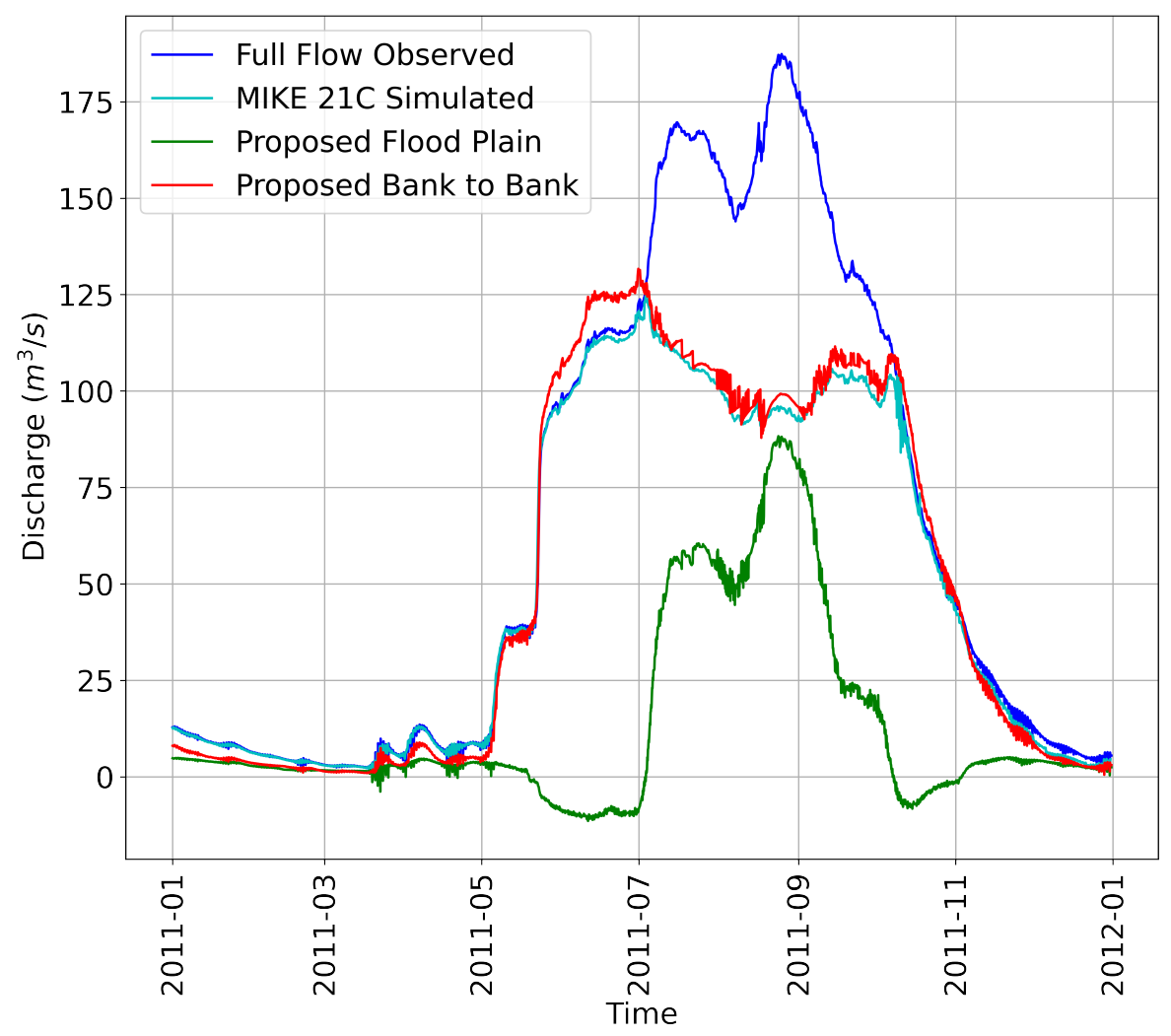

Figure 6: Discharge Comparison.

\begin{tabular}{|c|c|c|c|c|c|}
\hline Multiple R & 0.9982 & & & & \\
\hline R Square & 0.9964 & & & & \\
\hline Adjusted R Square & 0.9964 & & & & \\
\hline Standard Error & 2.8799 & & & & \\
\hline Observations & 2913 & & & & \\
\hline ANOVA & $\mathrm{df}$ & SS & MS & $\mathrm{F}$ & Significance $\mathrm{F}$ \\
\hline Regression & 1 & 6839564.952 & 6839564.952 & 824633.7305 & 0 \\
\hline Residual & 2911 & 24144.0203 & 8.2940 & & \\
\hline Total & 2912 & 6863708.972 & & & \\
\hline & Coefficients & Standard Error & t Stat & P-value & \\
\hline Intercept & -2.9032 & 0.0797 & -36.3990 & 2.0782E-239 & \\
\hline MIKE21C-Q & 1.0811 & 0.0011 & 908.0934 & 0 & \\
\hline & & Lower 95\% & Upper 95\% & Lower $95.0 \%$ & Upper $95.0 \%$ \\
\hline & & -3.0596 & -2.7468 & -3.0596 & -2.7468 \\
\hline & & 1.0788 & 1.0834 & 1.0788 & 1.0834 \\
\hline
\end{tabular}

Table 1: Regression statistics of discharge comparison. 


\section{Conclusion and Recommendation}

Morphological and hydrological knowledge of watershed can be significantly understood by measurement of the bank-to-bank flow and flood plain flow. Hence, this program has significant potential in the context of Morphology and hydrology of watershed. The consideration of local acceleration along with new numerical scheme can perfectly mimic the natural separation of flood plain flow. Furthermore, power spectral analysis Sarker (2021e) of these extracted discharge could be helpful to understand the accuracy and nature of the flood that can be subjected to further study.

\section{References}

Dottori, F., Martina, M., and Todini, E. (2009). A dynamic rating curve approach to indirect discharge measurement. Hydrology and Earth System Sciences, 13(6):847-863.

Koussis, A. (2009). Comment on "a dynamic rating curve approach to indirect discharge measurement" by dottori et al.(2009). Hydrol. Earth Syst. Sci, 14:1093-1097.

Morlot, T., Perret, C., Favre, A.-C., and Jalbert, J. (2014). Dynamic rating curve assessment for hydrometric stations and computation of the associated uncertainties: Quality and station management indicators. Journal of Hydrology, 517:173-186.

Reitan, T. and Petersen- $\varnothing$ verleir, A. (2011). Dynamic rating curve assessment in unstable rivers using ornstein-uhlenbeck processes. Water Resources Research, 47(2).

Reza, A. A., Sarker, S., and Asha, S. A. (2014). An application of 1-d momentum equation to calculate discharge in tidal river: A case study on kaliganga river. Tech. J. River Res. Inst, 2:77-86.

Sarker, S. (2021b). Investigating topologic and geometric properties of synthetic and natural river networks under changing climatic. UCF STARS.

Sarker, S. (February 2021d). A short review on computational hydraulics in the context of water resources engineering. engrXiv, DOI: https://doi .org/10.31224/osf .io/t4bne.

Sarker, S. (July 2021c). Pipe network design and analysis: An example with watercad. engrXiv, DOI: https://doi.org/10.31224/osf.io/c3aky.

Sarker, S. (July 2021e). A story on the wave spectral properties of water hammer. engrXiv, DOI: https://doi.org/10.31224/osf.io/nhuzq.

Sarker, S. (March 2021a). Hydraulics lab manual. engrXiv, pages 1-66, DOI: https://doi.org/10.31224/osf.io/mxcvw.

Sarker, S., Veremyev, A., Boginski, V., and Singh, A. (2019). Critical nodes in river networks. Scientific Reports, 9(1):1-11. 